\title{
Pulmonary function tests and high resolution computed tomography of the lungs in patients with rheumatoid arthritis
}

Bernard Cortet, Thierry Perez, Nicolas Roux, René-Marc Flipo, Bernard Duquesnoy, Bernard Delcambre, Martine Rémy-Jardin

\begin{abstract}
Objective-To compare the results of pulmonary function tests (PFTs) and high resolution computed tomography (HRCT) of the lungs in rheumatoid arthritis (RA) patients.

Methods-Sixty eight patients (54 women, 14 men) fulfilling the revised criteria for RA were consecutively included in a transversal prospective study. Their mean age was 58.8 years (range: $35-82$ ) and the mean duration of the disease was 12 years (range: 5-16). Rheumatoid factor was positive in 52 patients $(76.5 \%)$. Fifty two patients $(76.5 \%)$ were lifelong nonsmokers. Detailed medical and drug histories were obtained. PFTs comprised spirometry and gas transfer measurements. Results for PFTs were expressed as percentage of predicted values for each individual adjusted for age, sex, and height. HRCT was undertaken with a Siemens Somatom Plus.
\end{abstract}

Results-A significant decrease of FEV1/ FVC, FEF25\%, FEF50\%, FEF75\%, FEF25-75\%, and TLCO was observed $(p<0.05)$ and $13.2 \%$ of the patients had a small airways involvement defined by a decrease of FEF25-75\% below 1.64 SD. The most frequent HRCT findings were: bronchiectasis $(30.5 \%)$, pulmonary nodules $(28 \%)$, and air trapping $(25 \%)$. The patients with small airways involvement had a high frequency of recurrent bronchitis $(75 \% v 34 \%, p=0.05)$ and bronchiectasis $(71 \% \quad v \quad 23 \%, p=0.019)$. The patients with bronchiectasis were characterised by low values of FEV1, FVC, FEF25-75\%, and TLCO $(p<0.01)$, a high prevalence of small airways involvement $(29 \% v 5 \%, p=0.019)$, and a low prevalence of HLA DQA1 ${ }^{\star} 0501$ allele $(14 \% v 33 \%$, $\mathrm{p}<0.05$ ).

Conclusion-This study suggests a significant association between small airways involvement on PFTs and bronchiectasis on HRCT in unselected RA patients.

(Ann Rheum Dis 1997;56:596-600)

CHRU Lille, Hôpital Calmette, Lille, France

Correspondence to: Dr B Cortet, Department of Rheumatology, CHRU Lille, Hôpital R Salengro, 2 Avenue Oscar Lambret, 59037, Lille Cedex, France.

Accepted for publication 30 June 1997 well known extra-articular manifestation and might be the second cause of death after infection. ${ }^{1}$ Although interstitial lung disease is a well known manifestation of RA, small airways involvement may be the commonest form of RA lung involvement. ${ }^{2-4}$ Apart from pulmonary function tests (PFTs), other non-invasive tools such as high resolution computed tomography of the lungs (HRCT) have been shown to be of interest in the assessment of rheumatoid lung disease. ${ }^{5-8}$ Using HRCT, bronchiectasis seems to be one of the most frequent lung manifestations particularly in patients complaining of respiratory symptoms ${ }^{8}$ and its frequency ranges from $20 \%$ to $30 \%$ according to the authors. ${ }^{7}{ }^{8}$ However few studies have assessed both the use of HRCT and PFTs in RA patients. ${ }^{67}$

This prospective study aimed to compare HRCT and PFTs in unselected RA patients in the assessment of pulmonary involvement.

\section{Methods}

PATIENTS

This prospective study was conducted in one department of rheumatology from October 1994 to January 1996 and included 68 unselected outpatients with RA as defined by the ARA classification. ${ }^{9}$ None of the patients had previously been exposed to silica to avoid confusion between rheumatoid and pneumoconiotic lung lesions. The systematic evaluation of their lung changes was approved by the hospital ethics committee and all patients gave written informed consent to participate.

Detailed medical smoking (one pack year = 20 cigarettes daily for one year) and drug histories were obtained. Rheumatological evaluation included the assessment of the following parameters: morning stiffness duration, number of swollen joints, Ritchie articular index ${ }^{10}$ Steinbrocker classification, ${ }^{11}$ health assessment questionnaire, ${ }^{12}$ erythrocyte sedimentation rate, $C$ reactive protein concentration, HLA DRB1, DQ A and B genotypes. DRB1 genotype was determined by polymerase chain reaction-restriction fragment length polymorphism method (PCR-RFLP) as proposed by Danzé et al. ${ }^{13} \mathrm{DQ} \mathrm{A}$ and B were typed by PCR followed by probing with sequence specific oligonucleotides. The presence of Sjögren's syndrome was diagnosed according to the European criteria. ${ }^{14}$ Radiographs of hand were performed to calculate the Larsen's score. ${ }^{15}$ Pulmonary evaluation comprised questions about the presence of any respiratory symptom such as dyspnoea, cough or sputum production and a thorough physical examination. 
PULMONARY FUNCTION TESTS

PFTs were performed on the Medical Graphics PF/DX and on the body plethysmography system 1085 (Medical Graphics). PFTs included forced expiratory volume in one second (FEV1), forced vital capacity (FVC), FEV1/FVC, forced expiratory flow at $25 \%$ of the vital capacity (FEF25\%), forced expiratory flow at $50 \%$ of the vital capacity (FEF50\%), forced expiratory flow from $25 \%$ and $75 \%$ of vital capacity (FEF25-75\%), residual volume (RV), total lung capacity (TLC), gas transfer factor measurement (TLCO), and gas transfer factor measurement (TLCO)/alveolar volume $\left(\mathrm{V}_{\mathrm{A}}\right)$. Observed values were compared with those predicted for age, sex, and height. ${ }^{16}$ The results were expressed as percentage. According to the results of PFTs and on the basis of a decrease of PFT values below 1.64 residual $\mathrm{SD},{ }^{16}$ three groups were defined: group 1: large airways obstruction defined by a low FEV1/FVC ratio, group 2: small airways involvement defined by a low FEF25-75\% ratio in the absence of reduced FEV1/FVC ratio and in the absence of restrictive syndrome, and group 3: restrictive disorder defined by a decrease of TLC, FVC, and FEV1 with a normal FEV1/FVC ratio. This threshold $(-1.64 \mathrm{SD})$ is, when data are normally distributed, at the lower $90 \%$ confidence limit.

\section{HIGH RESOLUTION COMPUTED TOMOGRAPHY OF} THE LUNGS

HRCT of the thorax was performed with a SIEMENS Somatom Plus (Erlangen, Germany). Serial slices were taken through the chest, each $1 \mathrm{~mm}$ in width and $10 \mathrm{~mm}$ apart. Technical factors were $137 \mathrm{KV}$ and $255 \mathrm{~mA}$. Images were reconstructed using a high spatial frequency algorithm for parenchymal analysis. HRCT studies were performed at the suspended end inspiratory volume with one second scan time; patients were scanned in the supine position. In cases of articular limitation especially involving the shoulders, HRCT was performed with the patient's arms positioned alongside the body without any side effects on the image quality. The HRCT examinations were interpreted by two experienced radiologists in the absence of clinical information and decision was obtained by concensus. Multiple radiological criteria for the diagnosis of lung involvement were assessed. The screened abnormalities were: nodules; ground glass attenuation (visibility of the bronchi and the vessels); honeycombing defined as areas of cystic spaces with thickened walls; bron-

Table 1 Activity and disability parameters

\begin{tabular}{lll}
\hline Activity and disability parameters & Mean (SD) & Median (range) \\
\hline Morning stiffness duration (min) & $78(87.8)$ & $45(0-300)$ \\
Number of swollen joints & $1.9(2.4)$ & $1(0-10)$ \\
Ritchie articular index & $7.9(6.4)$ & $7(0-27)$ \\
Steinbrocker classification & $2.4(0.7)$ & $3(1-4)$ \\
HAQ & $1.67(0.74)$ & $1.75(0-2.88)$ \\
Erythrocyte sedimentation rate & $48(29.6)$ & $44(2-130)$ \\
C reactive protein (mg/l) & $43(45.3)$ & $29(0-253)$ \\
Larsen's score (wrist) & $2.5(1.4)$ & $3(0-5)$ \\
Larsen's score (metacarpophalangeal joint) & $2.5(1.7)$ & $2(0-5)$ \\
Larsen's score (interphalangeal joint) & $1.5(1.6)$ & $1(0-5)$ \\
\hline
\end{tabular}

$\mathrm{HAQ}=$ health assessment questionnaire. chiectasis defined as bronchial dilatation, often with thickening of the wall according to the criteria of Naidich et $a l,{ }^{1718}$ air trapping defined by a decreased attenuation of pulmonary parenchyma, especially manifest as less than normal increase in attenuation during expiration; and pleural effusion.

STATISTICAL ANALYSIS

The results of FEV1, FVC, FEV1/FVC, FEF25\%, FEF50\%, FEF75\%, FEF25-75\%, TLCO, TLCO/ $\mathrm{V}_{\mathrm{A}}$ are expressed as the percentage of the predicted value for each individual adjusted for age, sex, and height. Group data are expressed as mean (SD), median, and range if necessary (activity and disability parameters). Statistical comparisons were made using Student's $t$ test for unpaired data or Mann-Whitney U test as appropriate. Comparisons between patients with and without bronchiectasis concerning PFT results was made using raw data apart for $\mathrm{TLCO} / \mathrm{V}_{\mathrm{A}}$ (percentage of the predicted value). One way analysis of variance was made to study the influence of treatment on PFTs. Contingency tables were analysed for statistical significance using the $\chi^{2}$ test and Fisher's exact tests as appropriate. A probability value of $\leq 0.05$ was considered to be statistically significant.

\section{Results}

RA FINDINGS AND PULMONARY SYMPTOMS

There were 68 patients (54 women, $79.4 \%$ ). Their mean (SD) age was 58.8 (10.6) years. The mean (SD) duration of the the disease was 12 (9.2) years. Table 1 summarises the activity and disability parameters. Subcutaneous rheumatoid nodules were noted in 24 cases $(35.3 \%)$, and 14 patients $(20.6 \%)$ were suffering from Sjögren's syndrome. There was no evidence of other extra-articular manifestations and particularly vasculitis. Fifty three patients were receiving corticosteroids with a mean duration of four years and $46(64.7 \%)$ were taking non-steroidal anti-inflammatory drugs (NSAIDs). Thirteen patients (19.1\%) were not receiving any second line drug. Eighteen patients $(32.7 \%)$ were taking methotrexate, $12(21.8 \%)$ intra-muscular gold, 11 sulphasalazine $(20 \%)$, six hydroxychloroquine $(10.9 \%)$, six tiopronin (sulphydryl compound, $10.9 \%)$, and two cyclosporin A $(3.7 \%)$. Rheumatoid factor was positive in 52 patients $(76.5 \%)$. Shared epitope positive (DRB1 0101,0102,0401,0404,0405,0408,1001) DR4 alleles were observed in 30 patients (44\%).

Fifty two patients $(76.5 \%)$ had never smoked and $16(23.5 \%)$ were current or ex-smokers. The mean cigarette consumption was 25.7 (22.3) pack years. Twenty five patients $(36.8 \%)$ were complaining of recurrent bronchitis (mean: twice a year), nine patients $(13.2 \%)$ had a history of wheeze, five $(7.4 \%)$ had pneumonia confirmed radiologically, three $(4.4 \%)$ had pleurisy, and seven $(10.3 \%)$ had had pulmonary tuberculosis. Forty seven patients $(69.1 \%)$ were complaining of respiratory symptoms: dyspnoea $(n=40$, $58.8 \%)$, cough $(n=21,30.8 \%)$, and sputum production $(n=18,26.5 \%)$. Late inspiratory 
crackles were observed in 11 cases $(16.1 \%)$, coarse crackles in one case $(1.5 \%)$, sibilants in one case $(1.5 \%)$, and pleural rub in two cases $(2.9 \%)$.We did not find finger clubbing.

PFT FINDINGS

Table 2 summarises the results of PFTs. Compared with values predicted for age, sex, and height we found a significant decrease of FEV1/FVC, FEF $25 \%$, FEF50\%, FEF75\%, FEF25-75\%, and TLCO $(p<0.05)$. The results of PFTs were not different in the 52 non-smokers and in the 16 current or ex-smokers (table 3 ). The sole significant difference in PFTs on different treatments concerned FEV1/FVC, which was decreased in patients receiving tiopronin compared with those receiving intra-muscular gold: 70.8 (19.6) versus $81.8(6.6)(p=0.04)$.

Large airways obstruction was noted in six cases $(9 \%)$, small airways involvement in eight of 59 cases $(14 \%)$, and restrictive disorder in eight cases $(12 \%)$. Small airways involvement was not evaluated in nine cases: past history of radiation therapy for breast carcinoma $(n=3)$, pulmonary fibrosis $(n=2)$, sequelea of pulmonary tuberculosis $(n=3)$, major pleural effusion $(n=1)$.

\section{CT FINDINGS}

Table 4 summarises the results of HRCT. Air trapping was not assessed in four cases because of technical difficulties. In four patients ground glass attenuation was not assessed because of a past history of radiation therapy for breast carcinoma in three cases and major pleural effusion in one case. Bronchiectasis was not evaluated in nine cases because of a past history of radiation therapy for breast carcinoma in three cases, a pulmonary fibrosis in two cases, sequelea of pulmonary tuberculosis in three cases, and major pleural effusion in one case.

HRCT was abnormal in 55 patients $(80.9 \%)$. The most frequent abnormalities depicted on HRCT were bronchiectasis, which were found in 18 patients (30.5\%), pulmonary nodules $(28 \%)$, and air trapping $(25 \%)$.

\begin{tabular}{ll}
$\begin{array}{l}\text { Table } 2 \\
(S D))\end{array}$ & Results of PFT (data are expressed as mean \\
\hline PFT measurements & Percentage of the predicted values \\
\hline FEV1 & $93.1(23.9)$ \\
FVC & $98.9(20.9)$ \\
FEV1/FVC & $82.5(31.9)^{\star \star}$ \\
FEF25\% & $65(36)^{\star \star}$ \\
FEF50\% & $75.7(36.2)^{\star \star}$ \\
FEF75\% & $82.6(31.9)^{\star \star}$ \\
FEF25-75\% & $72.9(35.4)^{\star \star}$ \\
RV & $113.3(37)^{\star}$ \\
TLC & $101.5(21.7)$ \\
TLCO & $88.8(30)^{\star \star}$ \\
TLCO/ & $103.6(20.6)$
\end{tabular}

FEV1=forced expiratory volume in one second; FVC=forced vital capacity; FEV1/FVC; FEF $25 \%$ =forced expiratory flow at $25 \%$ of the vital capacity; FEF50\%=forced expiratory flow at $50 \%$ of the vital capacity; FEF $25-75 \%=$ forced expiratory flow from $25 \%$ and $75 \%$ of vital capacity; RV=residual volume TLC=total lung capacity; TLCO=gas transfer factor TLC=total lung capacity; TLCO $=$ gas transfer factor
measurement and TLCO/A. ${ }^{\star} \mathrm{p}<0.05, \star \star \mathrm{p}<0.01$ (comparison of the results observed with those predicted for age, sex, and height).
Table 3 PFT values (mean (SD)) according to smoking status

\begin{tabular}{lll}
\hline PFT measurements & $\begin{array}{l}\text { Non-smokers } \\
(n=52)\end{array}$ & $\begin{array}{l}\text { Current or ex-smokers } \\
(n=16)\end{array}$ \\
\hline FEV1 & $95.5(24.6)$ & $85.1(20.4)$ \\
FVC & $100.5(21.7)$ & $93.4(18.1)$ \\
FEV1/FVC & $78.9(10.2)$ & $74.8(10.9)$ \\
FEF25\% & $68.75(36.9)$ & $52.7(33.5)$ \\
FEF50\% & $78.7(36.9)$ & $65.6(33.4)$ \\
FEF75\% & $86.17(31.3)$ & $70.6(32.1)$ \\
FEF25-75\% & $75.8(35.7)$ & $63.5(33.8)$ \\
RV & $115(37.1)$ & $107.2(30)$ \\
TLC & $100.3(19.5)$ & $105.8(27.8)$ \\
TLCO & $89.1(29.8)$ & $87.8(31.6)$ \\
TLCO/V & $105.6(20.7)$ & $97.4(19.4)$ \\
\hline
\end{tabular}

There was no significant difference between the two groups studied. Abbreviations as shown in table 2 .

Table 4 HRCT findings

\begin{tabular}{ll}
\hline HRCT findings & Number of cases (\%) \\
\hline Abnormal pattern & $55 / 68(80.9)$ \\
Bronchiectasis & $18 / 59(30.5)$ \\
Nodules & $19 / 68(28)$ \\
Air trapping & $16 / 64(25)$ \\
Ground glass attenuation & $11 / 64(17.1)$ \\
Honeycombing & $2 / 68(2.9)$ \\
Pleural effusion & $1 / 68(1.5)$ \\
\hline
\end{tabular}

RESULTS ACCORDING TO PFT FINDINGS

Patients with airflow obstruction (low FEV 1/FVC)

Four of six patients of this group had a past history of wheeze and three were current or ex-smokers. This group did not differ from other patients in terms of activity and disability parameters or concerning the results of HRCT.

Patients with small airways involvement (low FEF25-75\%)

Seventy five per cent of these patients were non-smokers and seven of eight $(87 \%)$ were complaining of dyspnoea. The frequency of pulmonary symptoms was not significantly different in this group compared with other patients except for the history of recurrent bronchitis, which was more frequently observed in this group ( $75 \%$ versus $34 \%$, $\mathrm{p}=0.05)$. Activity and disability parameters were not significantly different in these patients compared with the others. The frequency of secondary Sjögren's syndrome was not significantly different in patients with and without small airways involvement. Bronchiectasis was more frequently depicted in this group than in other patients: $71 \%$ versus $23 \%, p=0.019$; one patient was excluded for bronchiectasis evaluation because of a past history of radiation therapy for breast cancer. Finally a non-significant increase of HLA DR2 and DR7 was found in this group compared with other patients: $25 \%$ versus $9 \%$ and $13 \%$ versus $7 \%$ respectively.

\section{Patients with restrictive syndrome}

Four of eight $(50 \%)$ of these patients were smokers. Pulmonary symptoms and particularly dyspnoea were not more frequently observed in this group. On HRCT a non-significant increase of honeycombing (two of eight, $25 \%$ versus none of $60,0 \%$ ) and ground glass attenuation $(37.5 \%$ versus $13.3 \%$ ) were found. 
RESULTS ACCORDING TO HRCT FINDINGS Bronchiectasis

The patients with bronchiectasis by HRCT were characterised compared with the others by a high frequency of non-smokers $(93.8 \%$ versus $70.8 \%, p=N S$ ), a high frequency of dyspnoea $(88.2 \%$ versus $56.1 \%, \mathrm{p}=0.03)$, a significant decrease of FVC (2.37 (0.6) versus 3.26 (1), $\mathrm{p}=0.003)$, FEV1 (1.77 (0.6) versus 2.56 (0.8), $\mathrm{p}=0.0016), \mathrm{FEF} 25-75 \%$ (1.66 (1.3) versus $2.52(1.1), p=0.009)$, TLC (4.9 (1.1) versus 5.5 (1.2), $\mathrm{p}=0.02)$, TLCO (5.5 (1.5) versus $7.7(2.1), \mathrm{p}=0.0003)$, and $\mathrm{TLCO} / \mathrm{V}_{\mathrm{A}}$ (94.6 (18.4) versus 107.8 (21), $\mathrm{p}=0.03)$. The patients with bronchiectasis were characterised by a high frequency of small airways involvement by PFTs $(29.4 \%$ versus 5\%, $\mathrm{p}=0.019$ ) and a high frequency of air trapping $(41.2 \%$ versus $19.5 \%, \mathrm{p}=\mathrm{NS})$. The frequency of Sjögren's syndrome was not significantly different in patients with and without bronchiectasis (33\% versus $22 \%$ ). Activity and disability parameters were not significantly different in patients with and without bronchiectasis. HLA DR genotype was not different according to the absence or the presence of bronchiectasis. The prevalence of DQA ${ }^{\star} 0501$ allele was significantly lower in patients with bronchiectasis compared with the others $(14 \%$ versus $33 \%, \mathrm{p}=0.03)$. According to the the presence or the absence of the shared epitope (HLADRB $1{ }^{\star} 0101,{ }^{\star} 0102,{ }^{\star} 0401$, ${ }^{\star} 0404,{ }^{*} 0405,{ }^{\star} 0408$, and ${ }^{\star} 01001$ ) we have compared the patients with and without bronchiectasis. No statistical difference was observed according to the presence or the absence of bronchiectasis.

\section{Air trapping}

PFT values were not statistically different in this group compared with those observed in other patients. Air trapping was not associated with the presence of large airways obstruction or small airways involvement.

Ground glass attenuation

Ground glass attenuation was more frequently depicted in smokers than in non-smokers $(50 \%$ versus $21 \%, \mathrm{p}=\mathrm{NS})$ and in patients suffering from recurrent bronchitis $(60 \%$ versus $36 \%, p=N S$ ). With PFTs these patients demonstrated a significant decrease FVC $(p=0.003)$ with normal values of $T L C O / V_{A}$.

\section{Discussion}

Our study suggests a high prevalence of small airways involvement in a population of unselected RA patients. Small airways obstruction is characterised in our study by a significant decrease of FEF $25 \%$, FEF $50 \%$, FEF75\%, and FEF25-75\% compared with the values predicted for age, sex, and height. Small airways obstruction is a well recognised manifestation of rheumatoid lung involvement $^{2-4}$; however the high prevalence of smokers in the previous published studies suggests that smoking might be the main cause of small airways involvement in RA. ${ }^{3}$ Conversely $76.5 \%$ of our patients were lifelong non-smokers suggesting that RA might explain the results of
PFTs. Although PFT values were generally lower in current or ex-smokers than in non-smokers, there was no significant difference between these two groups. This finding might be explained by the high standard deviation of the values of PFTs in the group of current and ex-smokers. Indeed the values of standard deviations are comparable in smokers and in non-smokers whereas their number are lower. Moreover it is possible that the low number of smokers and particularly current smokers $(n=7)$ did not permit the significant threshold to be achieved. The prevalence of small airways involvement defined on the basis of FEF $25-75 \%$ values below $1.64 \mathrm{SD}(14 \%)$ is lower than the one reported by Geddes et al perhaps because of the low prevalence of smokers in our study and the choice of the threshold for PFTs. However this threshold (-1.64 SD) was chosen because it is at the lower $90 \%$ confidence limit. The patients with small airways involvement had a high prevalence of recurrent bronchitis suggesting that respiratory tract infections might play a part in the pathogenesis of rheumatoid lung disease. ${ }^{19}$ Conversely our study does not support the hypothesis that secondary Sjögren's syndrome might play a part in the pathogenesis of small airways involvement, the frequency of secondary Sjögren's syndrome being similar in patients with and without small airways involvement confirmed by PFTs. In contrast Radoux et $a l^{20}$ have found a strong association between small airways involvement and secondary Sjögren's syndrome in RA patients. However we have not used the same criteria for the the diagnosis of Sjögren's syndrome as Radoux et $a l^{20}$ and this might explain this discrepancy. We have found a significant decrease of TLCO with a normal $\mathrm{TLCO} / \mathrm{V}_{\mathrm{A}}$ ratio suggesting the absence of major interstitial involvement in our population in agreement with the results of Linstow et $a l .{ }^{21}$ In the group of patients with large airways obstruction the abnormalities seem to be related to wheeze and smoking rather than RA as the frequencies of wheeze and smoking were high $(66.6 \%$ and $50 \%$ respectively). Restrictive syndrome was observed in eight of 68 patients $(12 \%)$ and might be related to parenchymal tissue inflammation. However only two patients of this group had an evidence of lung fibrosis using HRCT and TLCO/ $\mathrm{V}_{\mathrm{A}}$ was in the normal range in this group (101.8\%). Finally second line drugs and particularly methotrexate does not influence the results of PFTs. The patients receiving tiopronin (sulphydryl compound), however, had a low FEV1/FVC ratio compared with those receiving intramuscular gold. Obliterative bronchiolitis has been rarely reported in patients treated by tiopronin ${ }^{22}$ and none of the patients receiving tiopronin in our study had clinical evidence of obliterative bronchiolitis.

By HRCT the most frequent abnormality was bronchiectasis, which was found in $30.5 \%$. These results are in agreement with those published by Hassan et al and Cortet et al. ${ }^{78}$ Air trapping that is related to airways obstruction 
was observed in $25 \%$ and might be an interesting pattern in the assessment of rheumatoid lung disease.

The patients with small airways involvement confirmed by PFTs had a high prevalence of bronchiectasis compared with the others (71\% $v 23 \%$ ). Among patients with bronchiectasis confirmed by HRCT we have found a high prevalence of small airways involvement $(29.4 \% \vee 5 \%)$ and a significant decrease of FEF25-25\%. To our knowledge this the first study reporting an association between small airways involvement on PFT and bronchiectasis on HRCT. Indeed Hassan et al in a study including 20 lifelong non-smoking patients with RA have found bronchiectasis in $25 \%$ - that is, with a similar frequency to our own-but failed to demonstrate a high prevalence of small airways involvement in patients with bronchiectasis. This discrepancy could be because of the small number of patients in Hassan's study. Moreover data concerning the influence of bronchiectasies on PFT results were not shown in this study. Hassan $e t a l^{7}$ have found a high frequency of sicca syndrome $(80 \%)$ in patients with bronchiectasis whereas we have not found an association between bronchiectasis and secondary Sjögren's syndrome. Sicca syndrome could be related to varied causes, however, and not only to Sjögren's syndrome. In addition our patients with bronchiectasis had low $\mathrm{TLCO} / \mathrm{V}_{\mathrm{A}}$ values and these results are in agreement with those of Shadick $e t a l^{23}$ who have found a significant decrease of $\mathrm{TLCO} / \mathrm{V}_{\mathrm{A}}$ in $\mathrm{RA}$ patients with bronchiectasis.

This study suggests the absence of association between bronchiectasis and HLA DR genotype in agreement with the results of Hillarby et $a .^{24}$ Our data indicate a lower frequency of HLA DQA ${ }^{\star} 0501$ genotype in patients with bronchiectasis whereas Hillarby et $a l^{4}$ have found a higher frequency of HLA DQA $1^{\star} 0501$, DQB $1^{\star} 0201$, and HLA DQB ${ }^{\star} 0601$ genotypes in patients with RA and bronchiectasis compared with patients with RA without bronchiectasis. In comparison, the frequency of HLA DQA $1{ }^{\star} 501$ determinated in 233 healthy unrelated people from the north of France was $28 \%{ }^{25}$ and comparable with the one observed in our RA patients without bronchiectasis (33\%). The discrepancies between the study of Hillarby and our own do not seem to be the consequence of genetic differences between French and English populations because Hillarby et $a l^{24}$ have found a similar frequency of HLA DQA $1{ }^{\star} 501$ in their control population $(27 \%)$ than in our own. The main explanation might be that Hillarby et $a l^{4}$ have diagnosed bronchiectasis using clinical and radiological findings whereas in our study the diagnosis of bronchiectasis was based only on HRCT.

Finally we failed to find any association between ground glass attenuation on HRCT and low carbon monoxide diffusion capacity.

In summary this study suggests a strong association between small airways involvement confirmed by PFTs and bronchiectasis using HRCT. Small airways involvement might be related to an increased frequency of respiratory tract infections. Moreover bronchiectasis is not associated with poor activity or disability parameters. Finally our results do not support the hypothesis of a possible contribution of secondary Sjögren's syndrome in the pathogenesis of small airways involvement and bronchiectasis in RA.

The authors thank Pierre-Marie Danzé, Department of Biochemistry, University-Hospital of Lille, for determination of HLA DR- and DQ- typing.

1 Anaya JM, Diethelm L, Ortiz LA, Guttiriez M, Citera G, Welsh RA, et al. Pulmonary involvement in rheumatoid arthritis. Semin Arthritis Rheum 1995;24:242-54.

2 Geddes D, Webley H, Emerson P. Airway obstruction in rheumatoid arthritis. Ann Rheum Dis 1979;38:222-5.

3 Banks J, Banks C, Cheong B, Umachandran V, Smith AP, Jessop JD, et al. An epidemiological and clinical investigation of pulmonary function and respiratory. symptoms in patients with rheumatoid arthritis Q J Med 1992;307308:795-806.

4 Hassan WU, Keaney NP, Holland CD, Kelly CA. Bronchial reactivity and airflow obstruction in rheumatoid arthritis. Ann Rheum Dis 1994;53:511-4.

5 Fewins HE, McGowan I, Whitehouse GH, Williams J, Mallya R. High definition computed tomography in rheumatoid arthritis associated pulmonary disease. Br J Rheumatol 1991;30:214-6

6 McDonagh J, Greaves M, Wright AR, Heycock C, Owen JP, Kelly C. High resolution computed tomography of the
lungs in patients with rheumatoid arthritis and interstitial lung disease. Br J Rheumatol 1994;33:118-22.

7 Hassan WU, Keaney NP, Kelly CA. High resolution computed tomography of the lung in lifelong non-smoking patients with rheumatoid arthritis. Ann Rheum Dis 1995; 54:308-10.

8 Cortet B, Flipo RM, Rémy-Jardin $\mathrm{M}$, Coquerelle P, Duquesnoy B, Rémy J, et al. Use of high resolution computed tomography of the lungs in patients with rheumatoid arthritis. Ann Rheum Dis 1995;54:815-9.

9 Arnett FC, Edworthy SM, Bloch DA, McShane DJ, Fries JF, Cooper NS, et al. The American Rheumatism Association 1987 revised criteria for the classification of rheumatoid arthritis. Arthritis Rheum 1988;31:315-24.

10 Ritchie DM, Boyle JA, McInnes JM, Jasani MK, Dalakos TG, Grieveson P, et al. Clinical studies with an articular index for the assessment of joint tenderness in patients with rheumatoid arthritis. Q J Med 1968; 37: 393-406.

11 Steinbrocker O, Trager CH, Batterman RC. Therapeutic criteria in rheumatoid arthritis. JAMA 1949;37:393-406.

12 Guillemin F, Briançon S, Pourel J. Mesure de la capacité fonctionnelle dans la polyarthrite rhumatoïde: adaptation fonctionnelle dans la polyarthrite rhumatoide: adaptation Rhum Mal Ostéoartic 1991;58:459-65.

13 Danzé PM, Bianchi S, Fajardy I, Rousseaux J. An imroved strategy for HLA-DRB1 subtyping by digestion PCRamplified DNA with allele specific restriction endonucleases. Appl Theor Electrophor 1995;5:7-13.

14 Vitali C, Bombardieri S, Moutsopoulos HM, Balestrieri G, Bencivelli W, Bernstein RM, et al. Preliminary criteria for the classification of Sjögren's syndrome Results of a prospective concerted action supported by the European Community. Arthritis Rheum 1993;36:340-7.

15 Larsen A. Radiological grading of rheumatoid arthritis. An interobserver study. Scand J Rheumatol 1973;2:136-8.

16 Standardized lung function testing. Eur Respir J 1993;6 (suppl 16):5-52.

17 Naidich DP, McCauley DI, Khoury NF, Stitik FP, Siegelman SS. Computed tomography of bronchiectasis. Comput Assist Tomogr 1982;6:437-44.

18 Austin JHM, Müller NL, Friedman PJ, Hansell DM, Naidich DP, Rémy-Jardin M, et al. Glossary of terms for CT of the lungs: recommendations of the nomenclature committee of the Fleischner Society. Radiology 1996;200:327-31.

19 Bamji A, Cooke N. Rheumatoid arthritis and chronic bronchial suppuration. Scand J Rheumatol 1985;14:15-21.

20 Radoux V, Menard HA, Begin R, Decary F, Koopman WJ. Airways disease in rheumatoid arthritis patients. Arthritis Rheum 1987;30:249-56.

21 Linstow M, Ulrik CS, Kriegbum NJ, Backer V, Oxholm P A. 8-year follow-up study of pulmonary function in patients 8-year follow-up study of pulmonary function in patients
with rheumatoid arthritis. Rheumatol Int 1994;14:115-8.

22 Demaziere A, Maugars Y, Chollet S, Prost A. Non-fatal bronchiolitis obliterans possibly associated with tiopronin A case report with long term follow-up. Br J Rheumatol 1993;32:172-4

23 Shadick NA, Fanta CH, Weinblatt ME, O'Donnel W, Coblyn JS. Bronchiectasis. A late feature of severe rheumatoid arthritis. Medicine 1994;73:161-70.

24 Hillarby MC, McMahon MJ, Grennan DM, Cooper RG, Clarkson RWE, Davies EJ, et al. HLA associations in subjects with rheumatoid arthritis and bronchiectasis but not with other pulmonary complications of rheumatoid disease. Br J Rheumatol 1993;32:794-7.

25 Fajardy I, Damien E, Lourme C, Danzé PM. HLA class II polymorphism in the north of France. [Abstract]. Human Immunol 1996;47:52. 